\title{
a note on the illustrations
}

For many years Robert Irwin forbade photographic reproduction of his paintings. An early intuition in this regard hardened into an absolute conviction during the time he was creating his line, dot, and disc paintings. As will be seen in the text that follows, Irwin felt that a photograph would capture none of what the painting was about and everything that it was not about. That is, a photograph could convey image but not presence. Furthermore, many of the works of Irwin's middle years, particularly the late lines and the dot paintings, are virtually unreproducible: not even the "image" of the original, as it were, finds its way to the contact sheet. Which is why the first edition of this book, published in 1982, included no photographs of Irwin's work from 1957 through 1969.

Around the time of his column installations, however, in the late sixties, Irwin began to allow some photographic documentation. Although still dubious about the value of such documentation, he felt that the photos themselves were often sufficiently ambiguous to prevent the work's reduction to mere image. Furthermore, in many cases, photographic reproduction afforded the only ongoing record of pieces that seldom existed, in physical reality, more than a few weeks. For that reason, Irwin did allow the inclusion of some photographs of his more recent work in this volume.

Several years later, at the time of his retrospective at the Museum of Contemporary Art in Los Angeles, in 1993, Irwin, who'd begun to chafe under his reputation for fetishistic purity and abnegation in this regard ("The ban itself had never been the point, and yet that's what I was becoming known for, which was getting silly"), decided to relent on that photo ban altogether.

So this new edition of this book includes reproductions of work from all phases of Irwin's career. The same cautionary provisos, however, should be seen to apply. 